\title{
An Unusual, Paradoxical Arousal with Alprazolam in a Dependant User
}

\author{
Pritha Roy, Sujita Kumar Kar \\ Department of Psychiatry, King George's Medical University, Lucknow, India
}

\section{TO THE EDITOR}

Alprazolam is a well known benzodiazepine in management of anxiety. It has rapid onset of action and strong abuse potential. It produces sedation and compromises the motor as well as cognitive performance. ${ }^{1)}$ The abuse potential associated with alprazolam is due to its rapid onset of behavioural effects. ${ }^{2)}$ Due to its abuse potential, it is recommended as a second line agent in management of anxiety disorders. Several genetic mechanisms are involved in differential expression of behavior in chronic drug users, which may possibly explain the unusual or paradoxical behavioural manifestations. ${ }^{3)}$

A 40 year old male, from a rural background, a nonqualified health professional had consulted in psychiatry outpatients department for quitting alprazolam that he was taking in higher dose (up to 50 tablets of $0.5 \mathrm{mg}$ alprazolam/day). Eight years back, he was prescribed alprazolam $0.5 \mathrm{mg}$ /day by a general physician for management of his anxiety and disturbed sleep, which he was using regularly without further consultation.

Initially, anxiety symptoms relieved and he was able to do his chores and job well, but later, increasingly more number of tablets were required to alleviate anxiety and carry out his daily activities unhindered. He had started taking alprazolam in a higher dose (more than $5 \mathrm{mg} /$ day) in past seven years and during this period after taking 1-2 tablets of alprazolam $(0.5 \mathrm{mg})$, he used to experience light headedness, sedation and slurring of speech; that were controlled only on increasing the number of tablets. After consumption of 5-6 tablets together, he used to feel composed, confident, relaxed and could concentrate on desired jobs. His motor performance (walking smoothly,

\footnotetext{
Received: September 23, 2015 / Revised: October 22, 2015

Accepted: October 23, 2015

Address for correspondence: Sujita Kumar Kar, MD

Department of Psychiatry, King George's Medical University, Shah

Mina Road, Chowk, Lucknow, Uttar Pradesh 226003, India

Tel: +91-522-2265416, Fax: +91-522-2265416

E-mail: skkar1981@yahoo.com
}

writing without tremor) would also improve with such high doses. He had many unsuccessful attempts to quit alprazolam (resulting in withdrawal seizures) in the past years. Over past few months, he himself started reducing the number of tablets of alprazolam and at the time of consultation he was taking 20 alprazolam $(0.5 \mathrm{mg})$ tablets every day. There is no history of any other substance use, any other psychiatric illnesses or medical illness.

This case highlights a unique dose dependant response of alprazolam in a person who was dependant to it. Alprazolam is known to produce sedation in a dose dependant manner. ${ }^{4)}$ Higher dose of alprazolam is known to cause more sedation and impairment of cognitive functioning in healthy human volunteers. ${ }^{5)}$ Evidences also favour the dose dependent decline in psychomotor performance, anxiolysis and decreased intensity of fear-evoked startle response. ${ }^{6}$ However, another study revealed that benzodiazepines have no effect on the fear evoked startle response. ${ }^{7)}$ Paradoxical arousal and enhanced psychomotor performance was reported with higher dose of alprazolam in our patient, which is not reported in literature.

\section{REFERENCES}

1. Verster JC, Volkerts ER. Clinical pharmacology, clinical efficacy, and behavioral toxicity of alprazolam: a review of the literature. CNS Drug Rev 2004;10:45-76.

2. Reissig CJ, Harrison JA, Carter LP, Griffiths RR. Inhaled vs. oral alprazolam: subjective, behavioral and cognitive effects, and modestly increased abuse potential. Psychopharmacology (Berl) 2015;232:871-883.

3. Nestler EJ. Transcriptional mechanisms of drug addiction. Clin Psychopharmacol Neurosci 2012;10:136-143.

4. Osman OT, Hsiao JK, Potter WZ. Dose-dependent effects of intravenous alprazolam on neuroendocrine, biochemical, cardiovascular, and behavioral parameters in humans. Psychopharmacology (Berl) 1993;111:295-300.

5. Vermeeren A, Jackson JL, Muntjewerff ND, Quint PJ, Harrison EM, O'Hanlon JF. Comparison of acute alprazolam $(0.25,0.50$ and $1.0 \mathrm{mg})$ effects versus those of lorazepam $2 \mathrm{mg}$ and placebo on memory in healthy volunteers using laboratory and telephone tests. Psychopharmacology (Berl) 1995;118:1-9.

6. Riba J, Rodríguez-Fornells A, Urbano G, Morte A, Antonijoan R, Barbanoj MJ. Differential effects of alprazolam on the

(a) This is an Open-Access article distributed under the terms of the Creative Commons Attribution Non-Commercial License (http://creativecommons.org/licenses/by-nc/3.0) which permits unrestricted non-commercial use, distribution, and reproduction in any medium, provided the original work is properly cited. 
baseline and fear-potentiated startle reflex in humans: a dose-response study. Psychopharmacology (Berl) 2001;157: 358-367.

7. Baas JM, Grillon C, Böcker KB, Brack AA, Morgan CA 3rd, Kenemans JL, et al. Benzodiazepines have no effect on fear-potentiated startle in humans. Psychopharmacology (Berl) 2002;161:233-247. 